\title{
EN TORNO A LOS CONCEPTOS DE ENTE EN POTENCIA Y ENTE EN ACTO EN TOMÁS DE AQUINO Y EN FRANCISCO SUAREZ
}

\section{Regarding the Concepts of Being in Potency and Being in Act in Thomas Aquinas}

Oscar Edmundo Yangali Núñez*

Recepción: 21-04-18

Aceptación: 07-05-18

\section{RESUMEN}

En el presente trabajo pretendo exponer los pareceres de Tomás de Aquino y de Francisco Suárez sobre lo que distingue al ente en potencia del ente en acto, con el fin de establecer una comparación entre ambos autores y señalar por qué y con qué fin ha cambiado esta concepción entre los mismos. Primero, examino cuál es el principio de individuación de los entes en general, y la diferencia inicial que hallamos entre estos dos pensadores sobre la relación forma y materia. Segundo, evalúo en qué consiste lo que es el fundamento de nuestro conocimiento y la noción de semejanza. Y, finalmente, desarrollo en qué ha cambiado el entendimiento de lo real e individual en este tránsito escolástico a favor de la constitución de lo que es esencialmente un individuo.

\section{PALABRAS CLAVE}

Individuo, conocimiento, realidad, potencia, acto

\begin{abstract}
In the present work I intend to expose the views of Thomas Aquinas and Francisco Suarez on what distinguishes the potential entity from the entity in act. I establish a comparison between the two authors and in order to indicate why and to what purpose this conception has changed between them. First, I examine the principle of individuation of entities in general and the initial difference that we find between both thinkers on the relationship between form and matter. Second, I evaluate what constitutes the foundation of our knowledge and the notion of similarity. And finally I lay out the changes in the understanding of the real and the individual in this scholastic transit in favor of the constitution of what is essentially an individual.
\end{abstract}

\section{KEY WORDS}

Individual, knowledge, reality, potentiality, act

1 Asistente de docencia en la Pontificia Universidad Católica del Perú y docente en el Seminario Mayor Diocesano San José de Lurín: oscar.yangali87@gmail.com 


\section{INTRODUCCIÓN}

Sabido es que muchas han sido las comparaciones que suelen hacerse entre Tomás de Aquino y Francisco Suárez para explicar en qué consiste el pensamiento, sobre todo, de éste último y sobre si puede ser considerado un seguidor del tomismo o no. En el presente trabajo pretendo asumir este ejercicio comparativo con el fin de exponer las aparentes semejanzas que existen entre ambos pensadores con el fin de dilucidar una de las principales diferencias, la cual consiste fundamentalmente en la concepción sobre el principio de individuación de las creaturas en relación con el conocimiento directo del singular. Esta diferencia fundamental entre ambos pensadores estriba en su diferente concepción sobre los conceptos de ente en potencia y de ente en acto. De este modo, pretendo desarrollar las razones de base de por qué dicha diferencia y cuál es su repercusión para una nueva manera de entender al individuo en pro de su realidad particular acorde con Suárez.

\section{Los entes singulares y su principio de individuación}

Para comenzar, hay que decir que tanto Santo Tomás como Suárez aseveran la existencia de entes singulares, los cuales constituirán el primer paso de todo conocimiento posterior. Esto, pues se rechaza cualquier entidad separada al modo como, por ejemplo, entendió Platón las ideas. Dice Santo Tomás: "Platón sostenía que las formas de los seres naturales subsisten sin materia, $y$, consecuentemente, son inteligibles en cuanto tales, puesto que una cosa es inteligible en acto por el simple hecho de ser inmaterial" (De Aquino, 2009, p. 724). A lo que añade luego que, como Aristóteles no considera esta posición plausible, ya que las formas subsisten en las materias y por tanto no son inteligibles en acto, es menester que nuestro intelecto agente abstraiga las formas de la materia de los seres naturales (De Aquino, 2009, pp. 724725). Y es que es así como se entiende que nuestro conocimiento empieza por lo que los sentidos nos informan sobre los singulares, de manera que sea posible para nuestro intelecto abstraer la forma de los mismos. Sin embargo, cabe resaltar que no se admite la existencia de formas separadas sino de formas individuales en relación con las cosas mismas. Y, siguiendo aquello, Suárez no se distingue de lo dicho hasta aquí por Santo Tomás, ya que admite que "hay que decir que todas las cosas que son entes actuales o que existen o pueden existir inmediatamente, son singulares e individuales. Digo inmediatamente para excluir las razones comunes de entes que, como tales, no pueden existir inmediatamente" (Suárez, 1960a, p. 566), de modo que queda claro que no se admite la existencia de formas independientes de las existentes en los seres singulares.

Ahora bien, si bien es cierto que tanto Santo Tomás como Suárez se muestran aristotélicos en torno a nuestro conocimiento a partir de las cosas singulares, hay que examinar si en verdad no encontramos diferencias en torno a lo que constituye el ser de dichas cosas singulares. Y es que es aquí donde hallamos una diferencia fundamental acerca de lo que significa ser un ente individual en cuanto tal para Santo Tomás y para Suárez. Santo Tomás considera que lo que es principio de individuación de las substancias naturales es la materia (De Aquino, 2011 a, p. 273), ya que, como sabemos, la forma corresponde a lo que es esencial y común de todas las cosas singulares de una misma especie, de modo tal que la materia individualiza 
dicha forma para constituir los entes individuales. Por ello, la abstracción de la forma substancial consiste en la abstracción de la forma de la materia individual, de manera que, por ejemplo: "El entendimiento abstrae la forma de círculo de toda materia sensible" (De Aquino, 2009, p. 395). Así, abstraeríamos cualquier forma común en relación con los entes singulares de una misma especie, $y$, por lo mismo, ello significa que lo que constituye el principio de individuación o reconocimiento en cuanto tal de su individualidad consiste en su materia, mas no en su forma. No obstante, Suárez difiere de esta concepción, ya que considera que "toda sustancia singular [por sí misma o por su entidad es singular] y que no necesita ningún otro principio de individuación fuera de su entidad, o fuera de los principios intrínsecos de que consta su entidad" (Suárez, 1960a, pp. 644-645). Y es que, para Suárez, la forma no puede ser una cosa aparte de la materia porque ello implicaría que existen dos cosas de naturaleza distinta en una sola cosa individual que debería poseer una sola naturaleza. De modo que la forma individual sólo añade a la noción de naturaleza común algo de razón "Porque no niega esta opinión que en aquella entidad individual pueda distinguirse con la razón la naturaleza común de la entidad singular, y que de este modo el individuo añada sobre la especie algo conceptualmente distinto" (Suárez, 1960a, p. 645), lo cual, con orden a la tradición escolástica se denomina diferencia individual, pero no otra cosa.

Hay, por tanto, una diferencia fundamental acerca del principio de individuación para Santo Tomás y para Suárez. El primero considera que la forma no puede serlo ya que la forma determina a la materia en orden a la especificación, de modo que es la materia la que básicamente diferencia al individuo: "la forma da el ser a la materia, y por esto es imposible que la materia sea sin alguna forma; sin embargo, no es imposible que sea alguna forma sin la materia" (De Aquino, 2011 a, p. 284). Por otro lado, la opinión del segundo es distinta: "pues la materia y la forma, tomadas absolutamente son principios físicos de la especie de la sustancia compuesta y de su especificación; luego esta materia y esta forma serán los principios físicos del individuo y de su individuación" (Suárez, 1960a, p. 659). De modo que no es la sola materia la que diferencia al individuo sino tanto su propia forma cuanto su propia materia, esto es, su misma diferencia individual.

Así, vemos que no es posible señalar que ambos escolásticos postulen la misma tesis en torno al principio de individuación de los entes singulares. De hecho, no sólo será esta una diferencia superficial sobre un postulado, ya que veremos que esta diferencia será fundamental precisamente porque implicará una nueva concepción del ente individual por parte de Suárez con relación a los planteamientos de Santo Tomás.

\section{Fundamento del conocimiento en Santo Tomás y en Suárez}

En esta parte cabe desarrollar cómo es entendida ya no sólo la constitución del ente en cuanto tal sino cómo es posible acercarnos a su conocimiento a partir de aquella diferencia fundamental en torno al principio de individuación de los entes singulares. Ante todo, hay que resaltar el parecer de Santo Tomás para quien el conocimiento se realiza a partir de los entes singulares, aunque este conocimiento o abstracción se produzca conforme con el intelecto, el cual aprehende la forma del ente singular 
bajo un proceso de desmaterialización de la forma substancial. Es decir, no se abstrae la forma sino porque el intelecto es capaz de representar una forma conceptual en virtud de la semejanza hallada entre los entes de una misma especie. Dice Santo Tomás: "le corresponde [al intelecto] como propio el conocimiento de la forma presente en la materia corporal individual, si bien no tal como está en la materia" (De Aquino, 2009, p. 774), $\mathrm{y}$ es que es un menester de nuestro intelecto el aprehender la forma por medio de un proceso de desmaterialización el cual consiste en conocer la forma como inteligible a partir de las imágenes sensibles que los entes nos muestran. Por eso: "nuestro entendimiento conoce las realidades materiales abstrayendo de las imágenes. Y por medio de las realidades materiales así entendidas, llegamos al conocimiento de las inmateriales" (De Aquino, 2009, p. 774).

No parece ser esta la teoría del conocimiento que esboza Suárez, ya que éste asevera, de acuerdo con la distinción escolástica de concepto formal y concepto objetivo, que nuestro conocimiento puede ser dividido en estas dos etapas: "Se llama concepto formal al acto mismo $\mathrm{o}$, lo que es igual, al verbo con que el entendimiento concibe una cosa o una razón común" (Suárez, 1960a, p. 361). Este concepto formal no es otra cosa que el acto de entender que le muestra a nuestro intelecto la forma aprehendida de la realidad, ya que justamente indica la intencionalidad' ${ }^{\prime}$ que tiene nuestro intelecto con relación a las cosas del mundo; así, de otro lado: "Llamamos concepto objetivo a la cosa o razón que, propia e inmediatamente, se conoce o representa por medio del concepto formal" (Suárez, 1960a, p. 361). De manera que a todo ente de la realidad nuestro concepto formal lo aprehende por medio de un acto de entender y, posteriormente, representamos nuestro concepto objetivo de dicho ente para producir nuestra ciencia. Ésta, por supuesto, da origen a nuestra división de las cosas en géneros y especies. Sin embargo, hay que notar lo siguiente: "La diferencia, por lo tanto, entre el concepto formal y objetivo está en que el formal es siempre algo [res] verdadero y positivo, (...); por el contrario, el concepto objetivo no es siempre una verdadera cosa [res] positiva" (Suárez, 1960a, p. 361).

¿Por qué subrayar esta diferencia entre los conceptos formales y conceptos objetivos para Suárez? ¿Qué tiene de relevante para la diferencia fundamental que buscamos con base en el conocimiento que se esboza en comparación con la de Santo Tomás? Respondo que el empleo por parte de Suárez de aquella distinción entre los conceptos tiene que ver con una cierta inversión del orden tomista en que conocemos por medio de nuestro intelecto a los entes singulares. Es decir, que según Suárez nuestros conceptos formales se condicen con la existencia de los entes singulares, de manera que hablamos de un concepto que en cuanto tal se da únicamente sobre un ente singular, el cual es verdadero y positivo, y no así sobre una noción universal: "el concepto formal es siempre algo singular e individual, por ser algo producido por el entendimiento e inherente a él" (Suárez, 1960a, p. 361). Mientras que los conceptos objetivos sí pueden darse acerca de la reproducción de un ente singular como también de una

1 Intentio, para la escolástica, refiere tanto a la intencionalidad o ese "apuntar hacia afuera" como a la intensión, es decir, al significado o razón que subyace a una cosa la cual puede ser aprehendida y objetivada en el pensamiento. De modo que la intencionalidad escolástica es un tender hacia una intensión o razón esencial externa a nosotros y, por tanto, previa a nuestros conceptos. Por ello, Suárez llamará intención entendida o razón objetiva al concepto objetivo (Suárez, 1960a, p. 361). 
noción universal: "empero, el concepto objetivo a veces puede ser efectivamente una cosa singular e individual, (...) pero muchas veces es una cosa universal o confusa y común" (Suárez, 1960a, p. 361). De ahí que pueda haber conceptos objetivos sobre entes de razón, pero nunca conceptos formales de los mismos, ya que carecen de ser real positivo y, por tanto, verdaderamente inteligible.

Esta es una diferencia fundamental en lo que concierne al orden del conocimiento para nuestros autores, ya que aparentemente no se distinguen en lo que refiere a un conocimiento esencial de las cosas. No obstante, esta diferencia en el orden de nuestra aprehensión tendrá consecuencias en torno a lo que se concibe como el fundamento real de nuestro conocimiento: para Santo Tomás es la esencia tomada como la sola forma, para Suárez será la esencia tomada como el compuesto, la esencia tomada individualmente.

¿Cómo así es que ha ocurrido este tránsito entre las concepciones de estos autores? Pues bien, hay que señalar que, efectivamente, la teoría del conocimiento de Santo Tomás considera que la forma debe ser aprehendida para obtener nuestro conocimiento. Esto, porque Santo Tomás, en el fondo, si bien considera que la forma en cuanto tal es una forma individualizada por la materia en un ente singular, presupone una misma forma en ellos que pueda ser abstraída de las cosas. En efecto, toda la abstracción que comienza con la intención o término de nuestra operación intelectual, gracias al sentido y la imaginación, logra convertir dicha imagen abstrayendo de ella la forma de sus condiciones materiales para obtener la especie inteligible que pone al intelecto en acto, de modo que tanto esta imagen o intención como la especie inteligible no son sino una semejanza con relación a las cosas conocidas (De Aquino, 2007, pp. 171-172). Así, Santo Tomás señala que nuestro conocimiento de las cosas singulares no se realiza en virtud de ellas mismas en cuanto singulares, sino en la medida que nuestro intelecto logra aprehender una especie inteligible capaz de referir a estas cosas singulares. En otras palabras, no hay un conocimiento propiamente hablando de los entes singulares para Santo Tomás, si no es como un conocimiento derivado y posterior al de la especie inteligible.

Suárez aparentemente no piensa diferente de lo esbozado por Santo Tomás, sin embargo, si prestamos atención a lo que señala sobre lo que constituye formalmente a un individuo nos daremos cuenta que su discrepancia es ostensible:

(...) aunque cada individuo sea en la realidad formalmente uno, sin intervención de la consideración de la mente, sin embargo, muchos individuos de quienes afirmamos ser de la misma naturaleza, no son algo uno con verdadera unidad que exista en las cosas, a no ser sólo fundamentalmente o mediante el entendimiento. (...) porque ninguna unidad que exista en la realidad es común, según demostramos, sino que en las cosas singulares hay cierta semejanza en sus unidades formales, en la cual se funda la comunidad que el entendimiento puede atribuir a tal naturaleza en cuanto concebida por él, y esta semejanza no es propiamente unidad, porque no expresa la indivisión de las entidades en que se funda, sino sólo la conveniencia o relación, o la coexistencia de ambas. (Suárez, 1960a, pp. 704-705) 
De manera que, para Suárez, la forma individual de un ente no es la misma con relación a la de otro ente de la misma especie, sino que cada ente singular posee su propia forma individual y esta forma individual sólo guarda una relación de semejanza con otra. De este modo, el fundamento real del conocimiento esencial para Suárez no consiste en una esencia común que anteceda a la elaborada por nuestro intelecto, a no ser en una cierta semejanza entre las unidades formales la cual será tomada como una razón formal que no es real en sí misma, sino que tan sólo sirve de fundamento real. Cierto es que para Santo Tomás es importante la consideración de la semejanza que hay entre las cosas con el fin de concebir nuestros conceptos, pues de la naturaleza entendida proviene la noción de universal en cuanto se compara a las cosas que están fuera de nuestra mente al ser una semejanza de todas ellas (De Aquino, 2011 a, p. 281). Por ello Suárez, al comparar las doctrinas de Santo Tomás y de Escoto, se considera tomista en este punto:

Los autores citados se diferencian, empero, en el modo de explicar esta unidad formal; y la diferencia parece centrarse preferentemente en dos puntos: primero, en que Escoto cree que esta unidad formal, o la naturaleza misma en cuanto es formalmente una, es distinta formal y realmente de la unidad o diferencia individual. En cambio, otros [los tomistas] creen que sólo se distingue por razón; y la sentencia de éstos nos parece más admisible, (...). Segundo, en que Escoto no cree que esta unidad formal, (...) se multiplique numéricamente en los mismos individuos, sino que todos los individuos de la misma naturaleza tienen una sola e idéntica unidad formal, una sola-decimos-no sólo en la mente, sino en la realidad misma; o sea, que la naturaleza, tal como existe realmente en muchos individuos, tiene una unidad formal única. Otros [los tomistas] juzgan, a su vez, que la naturaleza tiene en cada individuo una unidad formal racionalmente distinta de la numérica, pero que ésta se multiplica en los individuos con las unidades individuales, y que no se trata, por lo tanto, de unidad alguna que sea idéntica en muchos individuos, según verdadera unidad real, sino sólo según cierta conveniencia o semejanza (Suárez, 1960a, pp. 698-699).

Sin embargo, queda claro por lo dicho anteriormente, que Suárez no hace la mejor descripción de sí mismo al considerarse tomista, ya que el fundamento real de nuestro conocimiento para él no será la semejanza entendida de igual modo a como la entiende Santo Tomás. Para éste, la semejanza es un vehículo para llegar al conocimiento de la forma, la cual constituye al ente en acto y le permite ser reconocible como de una misma especie con relación a otros, aunque no como un individuo en sí, de modo que nuestros universales constituyen para Santo Tomás el verdadero conocimiento en cuanto tal. Mientras que, para Suárez, la semejanza es lo único que antecede a nuestro intelecto, de modo que nuestros universales obtendrán su unidad de razón en nuestro concepto y no existirá unidad real anterior a los entes individuales.

\section{La noción de esencia real}

Ahora bien, hay que explicar cuál es el fundamento real de todo nuestro conocer de acuerdo con Santo Tomás y con Suárez, 
de manera que sea posible ultimar nuestro análisis en torno a la diferencia de sus concepciones sobre el ente como tal. Y es que esta diferencia fundamental descansa en la concepción del ente en potencia y del ente en acto, ya que para Santo Tomás la distinción real entre esencia y existencia le impide explicar qué es ese 'ente en potencia' que es anterior a lo que existe con excepción de una mera razón común o causa ejemplar. Suárez, en cambio, se tomará el trabajo de explicar qué es ese 'ente en potencia' con relación al 'ente en acto', desarrollando una nueva concepción de lo que significa la esencia en cuanto tal.

Para ello, es necesario examinar cuál es el concepto de realidad, o de lo que se predica como real, en ambos autores. $\mathrm{Y}$ es que a primera vista parece que no hubiera diferencia porque Suárez hereda esta clasificación de la esencia real de la tradición escolástica:

En qué consiste que una esencia sea real, podemos explicarlo mediante una negación o una afirmación. Según el primer modo, esencia real decimos que es la que en sí no envuelve contradicción alguna, ni es mera ficción del entendimiento. En cambio, de acuerdo con el segundo modo, puede explicarse: primero, a posteriori, por el hecho de ser principio o raíz de operaciones o efectos reales, sea en el género de la causa eficiente, de la formal o de la material; (...). Segundo, puede explicarse a priori por la causa extrínseca (aunque esto no sea verdad de la esencia en absoluto, sino de la esencia creada), y en este sentido, decimos que es real la esencia que puede ser producida realmente por Dios y constituirse como ser de un ente actual (Suárez, 1960a, p. 419).
Así, esencia real para Suárez no es cualquier cosa que pudiéramos imaginar, sino, en primer lugar, aquello que no alberga intrínsecamente contradicción en el ser. De modo que la esencia real es, ante todo, inteligible. Luego, también cabe considerar a la esencia real lo que hallamos en la realidad en virtud de sus operaciones, así como todo aquello que Dios mismo puede crear. De ahí que también nuestros conceptos objetivos no sean sino representaciones válidas en la medida que sean correlativos a conceptos formales, ya que los conceptos objetivos fundados en la realidad serían aquellos que se fundan en la no contradicción hallada entre entes bajo una semejanza o razón formal (Suárez, 1960a, p. 708).

Hasta aquí, no parece que hubiera divergencia entre Santo Tomás y Suárez, ya que esencia real es básicamente todo aquello que es o que puede ser. De hecho, García López señala que ya en la metafísica tomista "lo real" se predica con analogía de atribución extrínseca, porque se puede predicar tanto de aquellas cosas que existen como de las que no siempre y cuando puedan existir, de las primeras con propiedad, no así empero de las segundas (2001, pp. 71-72). No hay, por tanto, distinción en cuanto al uso de lo que significa real para ambos autores, hasta que topamos con las siguientes palabras de Suárez:

De donde se comprende, finalmente, que el ente, considerado con precisión, en cuanto significado con valor de nombre, puede dividirse con propiedad en ser en acto y en ser en potencia, y que ser en acto es lo mismo que ente significado por dicha palabra considerada como participio, y que ambas cosas significan la razón de ser, ya precisa, ya determinada a la existencia actual, (...); el ser en potencia expresa también un ente real, en cuanto a 
la esencia real, contracto y determinado no por algo positivo, sino por la privación de existencia actual (1960a, p. 423).

Aquí notamos algo interesante con relación a Suárez, a saber, la subsunción de lo que se considera el ente como participio, o sea el ente en acto, al ente como nombre, es decir, a la esencia real, la cual puede ser tomada tanto como ente en potencia cuanto como ente en acto. De manera que, con estas palabras, Suárez sí modifica el esquema tradicional escolástico de ente como nombre y ente como participio porque le atribuye un ser real al ente en potencia, probablemente porque éste cumple ya con la primera condición arriba mencionada, a saber, la de la no contradicción e inteligibilidad.

Esto no significa que Suárez considere que una esencia antes de ser creada por Dios exista realmente en el mismo sentido que como existente extra-mental. Suárez tiene bien en claro que el ente en cuanto está en potencia, se distingue de la existencia actual como el no ente del ente (1963, p. 21). Toda esencia que no ha sido creada por Dios no posee por sí ningún verdadero ser real, y en tal sentido, prescindiendo del ser de la existencia, la esencia no es ninguna realidad, sino absolutamente nada (Suárez, 1963, p. 21). En definitiva, Suárez no considera real en cuanto existente a ninguna cosa, con excepción de Dios, que no haya sido creada ya por Él. ¿Cuál es, entonces la importancia de hacer explícita mención de que los entes en potencia y no sólo los entes en acto son seres reales? Pues bien, Suárez mismo muestra esa respuesta: "Juzgo que esta sentencia así explicada es absolutamente verdadera. Su fundamento consiste brevemente en que una cosa no puede estar constituida intrínseca y formalmente en la razón de ente real y actual por otra cosa distinta de ella misma" (1963, p.
21). De manera que ahora sí queda claro cuál es el propósito de la sutil distinción de Suárez con relación a Santo Tomás, a saber: señalar que todo ente en potencia se constituye como real por sí mismo tanto antes de existir como después. Por eso dijimos arriba que todo lo que existe $y$ puede existir inmediatamente para Suárez es singular. Dios no hace diferencia alguna en su ser real en cuanto a la individuación del ente, ora en potencia ora en acto, ya que no hay ninguna esencia real que anteceda a la esencia del individuo mismo. Así, no es sólo que Dios crea ex nihilo, sino que todo lo que crea posee su misma esencia primero en potencia y luego, al ser creado, su misma esencia en acto. Por lo tanto, la razón de fondo de por qué Suárez asevera la realidad de los entes en potencia no es porque considere existentes a los entes antes de existir, cayendo en patente contradicción, sino porque considera que lo real fundamental de todo ente en cuanto tal es lo mismo antes y después de ser creado dicho ente individual. En otras palabras, no hay esencia común real previa a las esencias individuales. Y "es en esto precisamente en lo que se distinguen las esencias de las criaturas de las cosas ficticias e imposibles, como la quimera, y éste es el sentido en el que se dice que las criaturas poseen esencias reales, aunque no existan" (Suárez, 1963, p. 23). Es decir, en que toda esencia creada posee su propia esencia individual tanto para Dios como para sí misma: "se dice que las poseen no de modo actual, sino potencial, no en virtud de su potencia intrínseca, sino de la potencia extrínseca del Creador" (Suárez, 1963, p. 23).

Ahora bien ¿̇cuál es la razón de fondo que permite a Suárez desarrollar esta diferencia entre el ente en potencia y el ente acto concluyendo que ambos sean reales? Pues bien, sigo aquí el parecer de García López, quien señala 
que el fundamento de esta diferencia entre Santo Tomás y Suárez radica en su noción de potencia (1976, pp. 113 115). Y es que Suárez guarda una diferencia fundamental con Santo Tomás en relación con la concepción de la potencia como un cierto acto. Santo Tomás no considera a la potencia como un acto, pues considera únicamente la distinción entre potencia y acto como principios del cambio o movimiento. Así, la potencia se relaciona con el acto como la materia con la forma; por ello: "por la forma, que es acto de la materia, la materia se hace ente en acto y esta determinada cosa" (De Aquino, 2011 a, p. 271). Para Santo Tomás, la potencia carece por completo de actualidad, por eso la materia se concibe como pura potencialidad. Así, la definición de los entes en potencia según Santo Tomás es:

(...) el ente en potencia es algo intermedio entre el puro no ente y el ente en acto. Luego, las cosas que se hacen naturalmente, no se hacen del no-ente en sentido absoluto, sino del ente en potencia. Por ello no es necesario que preexistan en acto las cosas que se hacen, (...), sino solamente en potencia (De Aquino, 201 lb, p. 97)

Para Suárez, ese "intermedio entre el puro no ente y el ente en acto" no es sino ininteligible, puesto que no se dice realmente qué es. Suárez reconoce que lo que es posible debe gozar de alguna actualidad y, por tanto, realidad con relación al poder de Dios, ya que, en caso contrario, sería algo simplemente imposible. A diferencia de Santo Tomás, señala que "la materia no se llama pura potencia respecto de todo acto metafísico, es decir, porque no incluya ningún acto metafísico; pues esto no puede ser verdad" (Suárez, 1960b, p.
432), y dice, además: "la materia no es de tal modo pura potencia que no sea algún acto entitativo relativo" (Suárez, 1960b, p. 433). Prieto López señala por eso: "Según Suárez, que en este aspecto se muestra fiel discípulo de Escoto, la materia prima no es pura potencia, sino algo que posee una actualidad propia, que, aunque inferior a la que aporta la forma, sin embargo, es suficiente para que el entendimiento pueda acceder a ella" (2013, p. 114). Esto explica que, para Suárez, y no para Santo Tomás, la distinción entre esencia y existencia sea sólo de razón, ya que no se trata de dos realidades sino de una misma realidad que primero no existe y luego existe, es decir, primero es ente en potencia y luego ente en acto (Suárez, 1963, p. 62). Copleston decía que: "(...) tomistas y suarecianos convienen, indudablemente, en el carácter contingente de la criatura. En lo que difieren es en el análisis de lo que quiere decir ser contingente" (2004, pp. 350-351), faltándole explicar, considerando que dicho ser contingente no deja de ser real tanto antes como después de pasar a la existencia. Y es que Copleston está comparando a ambos pensadores dando por sentada su congruencia más una cuestión de fe, a saber, que las creaturas son contingentes y no necesarias como Dios, de modo que está descuidando el desarrollo metafísico que soporta la definición del ente real como esencia individual según Suárez. De ahí que, por ejemplo "Pedro, no sólo es uno numéricamente, sino que también es uno esencialmente; y ambas unidades las posee en la realidad misma y no en virtud de la operación de nuestra mente" (Suárez, 1960a, p. 703). Una explicación insuficiente y parecida a la anterior la advertimos en Mas Herrera, ya que menciona que: "El litigio entre tomismo y suarecismo al respecto de la distinción ya real o ya de razón ent|r]e la esencia 
y la existencia, descansa, como se ve, sobre posiciones metafísicas anteriores, referentes a la naturaleza del ser" (1999, p. 121). Sin embargo, incluso habiendo reconocido ahí mismo que la esencia debe ser entendida en acto ya dentro de un orden real, no desarrolla qué significa que una esencia sea considerada real ni qué implicancias tiene esto. De donde se hace importante señalar que la distinción de razón entre la esencia y la existencia o esencia posible y esencia en acto, para Suárez, se da precisamente porque la esencia real es aquella que se constituye, sobre todo, individualmente como tal.

En conclusión, la distinción entre ente en potencia y ente en acto nos hace ver la divergencia fundamental entre Santo Tomás y Suárez, a saber, la consideración en torno al principio de individuación del ente. Por ello, la afirmación suareciana del conocimiento directo del singular, algo que para Santo Tomás sería impensable, ya que todo conocimiento propiamente sería del universal:

Nuestro entendimiento no puede conocer primaria y directamente lo singular de las cosas materiales. El porqué de esto radica en que el principio de singularización en las cosas materiales es la materia individual, y nuestro entendimiento, tal como dijimos (q. 85 a. 1), conoce abstrayendo la especie inteligible de la materia individual. (...) Indirectamente, y como por cierta reflexión, puede conocer lo singular, porque, como se dijo (q. 84 a. 7), incluso después de haber abstraído las especies inteligibles, no puede entender en acto por ellas a no ser volviendo a las representaciones imaginarias en las que entiende las especies inteligibles, como se dice en III
De Anima. (De Aquino, 2009, pp. 786-787).

Una epistemología inversa a la de Santo Tomás nos la muestra Suárez, ya que para éste el conocimiento del singular es directo:

(...) puede abstraerse una naturaleza común por la pura precisión de esa naturaleza respecto de uno solo de sus inferiores sin comparación alguna, (...) por ejemplo, cuando de solo Pedro prescindo simplemente las propiedades individuales y me detengo en la consideración de la naturaleza humana. (Suárez, 1960a, p. 762)

Y ya posteriormente:

(...) puede abstraerse una naturaleza común por comparación de los singulares o inferiores entre sí, como cuando al comparar a Pedro con Pablo, conozco que son semejantes en la naturaleza humana. Mas esta comparación supone la precisión anterior, porque supone que de ambos singulares se conoce que son de esa naturaleza, suponiendo, por lo mismo, el concepto de tal naturaleza en cuanto se la prescinde de cada uno de los individuos. (Suárez, 1960a, p. 762)

Así, esencia real es fundamentalmente, para Suárez, el ente individual y no tan sólo una forma o naturaleza común en cierto modo independiente de los mismos entes singulares que existen o pueden existir, aunque es cierto que no por eso Suárez no reconozca valor real a nuestro conocimiento de los universales. De ahí que Iturrioz haya dicho: "Suárez, 
como Ockham, admite que es posible conocer directamente el singular. Pero (...), admite el conocimiento del universal y reconoce a éste valor objetivo con la misma objetividad y con el mismo realismo que Santo Tomás y que todos los tomistas" (I1949, p. 263). Sin embargo, hay que señalar que para Suárez el conocimiento directo es del singular e indirecto el del universal, de modo que no puede ser catalogado como tomista por más que sea un realista metafísico. Por ello, Larrainzar señala sobre la epistemología de Suárez que: "se comprende que su gnoseología esté orientada a justificar una intelección directa de objetos singulares y concretos, o la realidad de un conocimiento universal que comienza siempre en esas especies inteligibles de los singulares" (1977, pp. 107-108), puesto que nuestras razones primeras las cuales podemos abstraer inmediatamente son siempre esencias individuales. Esto, de acuerdo con lo desarrollado, se debe principalmente al principio de individuación considerado por ambos autores, lo que es una diferencia fundamental debido a que el conocimiento conceptual objetivo según Suárez es producido en nosotros con fundamento en la realidad, pero no es una abstracción entendida como la desmaterialización tomista de una forma común. Más bien, es un entender u objetivar en el concepto la semejanza entre las diversas unidades formales de la realidad; en caso contrario, no habría por qué Suárez postulase un conocimiento directo del singular.

Ya que para Santo Tomás la materia es la que individualiza a la forma es preciso desmaterializar al ente para obtener de él lo que constituye su propio acto. Mientras que, para Suárez, ya que el principio de individuación lo constituye el mismo ente individual, es preciso señalar que el verdadero conocimiento es constituido por la experiencia con el mismo individual y no a través de alguna otra cosa que no sea dicho ente individual, ya que su actualidad esencial con relación a nuestro entendimiento la constituye él mismo. Me gustaría nos preguntáramos: ¿qué podríamos aprender del tratamiento de Suárez en relación con la concepción de Santo Tomás? Quizá habría que contestar con que, para Suárez, se profundiza todavía más en una constitución subjetiva del ente en cuanto tal en cuanto a una aproximación más cercana de la realidad del individuo en su dimensión integral, tal y como hizo en su momento Santo Tomás con relación a los pensadores anteriores.

\section{REFERENCIAS}

COPLESTON, F. (2004) Historia de la filosofía, Vol. III, De Ockham a Suárez, Editorial Ariel, S. A., Barcelona.

DE AQUINO, T. (2011a) El ente y la esencia, EUNSA, Pamplona.

DE AQUINO, T. (2011 b) Comentario a la Física de Aristóteles, Pamplona.

DE AQUiNo, S. T. (2009) Suma de Teología, Biblioteca de Autores Cristianos, Madrid.

DE AQUINO, S. T. (2007) Suma contra los gentiles, Biblioteca de Autores Cristianos, Madrid.

GARCÍA LÓPEZ, J. (1976) Estudios de metafísica tomista, EUNSA, Pamplona.

GARCÍA LÓPEZ, J. (2001) Metafísica tomista, EUNSA, Pamplona.

ITURRIOZ, J. (1949) Estudios sobre la Metafísica de Francisco Suárez, S. I., Colegio Máximo de S. I. de Oña, Madrid. 
LARRAINZAR, C. (1977) Una introducción a Francisco Suárez, EUNSA, S. A., Pamplona.

MAS HERRERA, O. (1999) "La Esencia y la Existencia: Santo Tomás y Francisco Suárez", en: Revista de Filosofía de la Universidad de Costa Rica, N 91, Vol. XXXVII, San José.

PRIETO LÓPEZ, L. (2013) Suárez y el destino de la metafísica, De Avicena a Heidegger, Biblioteca de Autores Cristianos, Madrid.

SUÁREZ, F. (1960a) Disputaciones Metafísicas, Edición y traducción de Sergio Rábade Romeo, Salvador Caballero Sánchez y Antonio Puigcerver
Zanón, 7 vol., Biblioteca Hispánica de Filosofía, Editorial Gredos, Madrid. Volumen I.

SUÁREZ, F. (1960b) Disputaciones Metafísicas, Edición y traducción de Sergio Rábade Romeo, Salvador Caballero Sánchez y Antonio Puigcerver Zanón, 7 vol., Biblioteca Hispánica de Filosofía, Editorial Gredos, Madrid. Volumen II.

SUÁREZ, F. (1963) Disputaciones Metafísicas, Edición y traducción de Sergio Rábade Romeo, Salvador Caballero Sánchez y Antonio Puigcerver Zanón, 7 vol., Biblioteca Hispánica de Filosofía, Editorial Gredos, Madrid. Volumen V 